Check for updates

Cite this: RSC Adv., 2018, 8, 36375

Received 20th August 2018

Accepted 15th October 2018

DOI: $10.1039 / \mathrm{c} 8 \mathrm{ra06942e}$

rsc.li/rsc-advances

\section{Large-scale fabrication of waterborne superamphiphobic coatings for flexible applications $\uparrow$}

\begin{abstract}
Youfa Zhang, (D) *a Daozhou Yao, ${ }^{\text {a }}$ Shanlin Wang, ${ }^{\mathrm{b}}$ Zhen Xiao and Xinquan $\mathrm{Yu}^{\mathrm{a}}$
In recent years, there have been great achievements in superhydrophobic coatings. However, there are still some barriers restricting superhydrophobic coatings in practical applications, such as widely used organic solvents and poor oleophobicity. In this study, we proposed a method for fabricating absolutely waterborne superamphiphobic coatings in two steps. Firstly, we synthesized the waterborne $\mathrm{SiO}_{2}$ sol using methyltriethoxysilane, and then the $\mathrm{SiO}_{2}$ sol was modified in an aqueous system with a fluorocarbon surfactant. The results showed that the coating had contact angles of $160^{\circ}, 153^{\circ}$ and $150^{\circ}$ and sliding angles of $1^{\circ}, 4.7^{\circ}$ and $6.3^{\circ}$ with respect to water, soybean oil and hexadecane. Moreover, the coating could withstand $300{ }^{\circ} \mathrm{C}$ heating and immersion in various corrosive solutions for several hours. Furthermore, it is worth mentioning that the waterborne coating showed excellent performances in antifouling, self-cleaning, and damp-proof fields.
\end{abstract}

\section{Introduction}

The demand for water repellent and antifouling properties has been increasing gradually owing to severer and severer environmental problems. ${ }^{1-3}$ Inspired by the lotus leaf, superhydrophobic surfaces, having a greater water contact angle (CA) than $150^{\circ}$ and a lower sliding angle (SA) than $10^{\circ}$, were proposed in an attempt to satisfy the aforementioned demand. To our delight, superhydrophobic surfaces have tremendous potential applications in self-cleaning, ${ }^{4-7}$ anti-icing, ${ }^{8-13}$ drag reduction, ${ }^{14-16}$ water-oil separation ${ }^{17-22}$ and atmospheric water capture. $^{23-25}$ However, the superhydrophobic surfaces tend to lose their effects when exposed to external environments for a long time due to the presence of various organic contaminants, to a great extent. As a consequence, the question of how to improve the durability of superhydrophobic surfaces after long-term exposure to the outside has drawn the attention of researchers. Superamphiphobic surfaces, with both superhydrophobicity and superoleophobicity, are very desirable due to the fact that they are promising for solving the problems above. Nevertheless, it is much harder to fabricate superamphiphobic surfaces, which possess larger roughness and lower surface free energy. Several methods have been proposed

ajiangsu Key Laboratory of Advanced Metallic Materials, School of Materials Science and Engineering, Southeast University, Nanjing 211189, P. R. China. E-mail: yfzhang@seu.edu.cn

${ }^{b}$ School of Material Science and Engineering, Southwest University of Science and Technology, Mianyang 621010, PR China

$\dagger$ Electronic supplementary information (ESI) available. See DOI: 10.1039/c8ra06942e to prepare superamphiphobic surfaces, such as functionalization with nanoparticles, ${ }^{26}$ etching, ${ }^{27,28}$ lithography, ${ }^{29}$ templateassisted synthesis ${ }^{5}$ and sol-gel routes. ${ }^{30}$ Recently, SusarreyArce and his coworkers ${ }^{31}$ developed a method to fabricate arrays of microstructures via the reactive ion etching of a silicon wafer, which was covered by a patterned photoresist layer. Regrettably, it seems that with this method it was difficult to fabricate superamphiphobic surfaces on a large scale because of the complex process and costly equipment. Among various methods, wet-chemical processes by dip-coating or spraying are the focus of concern due to their great convenience for largescale fabricating with a low reliance on equipment.

To the best of our knowledge, most of the solvents that are used in the wet-chemical systems are organic, including ethanol, ${ }^{32}$ acetone, ${ }^{33}$ dimethylformamide (DMF), ${ }^{33}$ and tetrahydrofuran (THF), ${ }^{34}$ which are considered to be harmful to both the environment and human health. Consequently, it is impossible to prepare superamphiphobic coatings consisting of an organic solvent on a large scale. Water, known as a green and cost-effective solvent, is of great interest to scientists around the world. In recent years, Bayer and co-workers ${ }^{35}$ have reported the formation of a superamphiphobic surface through spraying an aqueous solution consisting of spherical and porous silicon dioxide nanopowder, hydrophilic fumed silica and waterborne acrylic fluorochemical dispersion on high temperature metallic substrates. However, most of the reported waterborne superamphiphobic coatings have an inaccessible preparation cost, restricting their further practical application.

Herein, we developed a simple, low-cost, environmentally friendly method to fabricate waterborne superamphiphobic coatings using methyltriethoxysilane, fluorinated alkyl silane 
and a fluorocarbon surfactant as the principal raw materials. Firstly, waterborne $\mathrm{SiO}_{2}$ sol was synthesized via a hydrolysis process of methyltriethoxysilane in water. The following step was the modification of the $\mathrm{SiO}_{2}$ sol through fluorinated alkyl silane in water with a fluorocarbon surfactant. Subsequently, the superamphiphobic coatings were prepared by spraying or dip-coating on glass, polyester fiber, copper foam and some other substrates. The coating showed an excellent superamphiphobic ability with contact angles of $160^{\circ}, 153^{\circ}$ and $150^{\circ}$ and sliding angles of $1^{\circ}, 4.7^{\circ}$ and $6.3^{\circ}$ with respect to water, soybean oil and hexadecane. Furthermore, the coating could be coated on various substrate surfaces, such as glass, copper foam and polyester fiber, it performed very well in terms of chemical durability and thermal stability and it has potential for practical use in antifouling, self-cleaning and damp-proof fields.

\section{Materials and methods}

\subsection{Materials}

Methyltriethoxysilane (MTES) was purchased from Tokyo Chemical Industry Co, Ltd. ForaperLe 323 (FL323) fluorocarbon surfactant was supplied by DuPont. $1 H, 1 H, 2 H, 2 H$-Peruorodecyltriethoxysilane (PFDTES) was purchased from Sikang New Material Co., Ltd. Tetraethoxysilane (TEOS), sodium dodecyl benzene sulfonate (SDBS), deionized water, ammonia solution $\left(\mathrm{NH}_{3} \cdot \mathrm{H}_{2} \mathrm{O}, 28 \mathrm{wt} \%\right)$ and other chemical reagents were purchased from Sinopharm Chemical Reagent Co., Ltd.

\subsection{Synthesis of waterborne $\mathrm{SiO}_{2}$ sol}

Firstly, $0.2 \mathrm{~g}$ SDBS, $2 \mathrm{~mL} \mathrm{NH} \mathrm{NH}_{3} \cdot \mathrm{H}_{2} \mathrm{O}$ and $36 \mathrm{~g}$ deionized water were mixed homogeneously via magnetic stirring for $15 \mathrm{~min}$. Then, $15.2 \mathrm{~g}$ methyltriethoxysilane was added to the solution dropwise. Subsequently, the mixed solution was left to stir at $60{ }^{\circ} \mathrm{C}$ for 12 to 60 hours to obtain waterborne $\mathrm{SiO}_{2}$ sol.

\subsection{Fabrication of the waterborne coatings}

First of all, $12.5 \mathrm{~g}$ fluorocarbon surfactant and $30 \mathrm{~g} \mathrm{\textrm {SiO } _ { 2 }}$ sol were added to $2 \mathrm{~L}$ deionized water with $100 \mathrm{~mL} \mathrm{NH} \cdot \mathrm{H}_{2} \mathrm{O}$ in it. After magnetic stirring for $10 \mathrm{~min}, 15 \mathrm{~mL}$ TEOS was added. Subsequently, $15 \mathrm{~mL}$ PFDTES was added dropwise to the system. The mentioned solution was left to stir at $600 \mathrm{rpm}$ at $45^{\circ} \mathrm{C}$ for $24 \mathrm{~h}$ to fabricate the waterborne coatings.

\subsection{Characterizations}

The microstructure of the sample surface was observed using field emission scanning electron microscopy (FESEM) and transmission electron microscopy (TEM). Static contact angles (CA) and sliding angles (SA) were determined at room temperature using an OCA 15 Pro contact angle meter to characterize the hydrophobicity of the specimens. The average CA values were determined by measuring the same sample at 3-5 different positions. The volume of the water droplet was $5 \mu \mathrm{L}$ for CA and $10 \mu \mathrm{L}$ for SA unless noted otherwise. The water droplet bouncing test was captured using a Photron FASTCAM Mini UX100 type high speed camera equipped with a Navitar 6000 zoom lens. The particle size distribution of the waterborne coatings and the infrared spectrogram of the $\mathrm{SiO}_{2}$ sol were measured using a Laser Particle Size Analyzer using Microtrac S3500 and Fourier transform infrared spectroscopy using Nicolet 5700. All the coatings were prepared by spraying or dipcoating using an airbrush (S-130, U-STAR) and padder (made by ourselves, for the purpose of squeezing extra liquids in fiber).

\section{Results and discussions}

\subsection{Preparation of the waterborne coatings}

The waterborne superamphiphobic coatings were prepared via a modified reaction between the $\mathrm{SiO}_{2}$ sol and $1 \mathrm{H}, 1 \mathrm{H}, 2 \mathrm{H}, 2 \mathrm{H}$ perfluorodecyltrichlorosilane (PFDTES), and the schematic for this is shown in Fig. 1a. First of all, $\mathrm{SiO}_{2}$ sol was synthesized using methyltriethoxysilane (MTES). The MTES was hydrolyzed in an aqueous system and sodium dodecyl benzene sulfonate (SDBS) was used to promote the solubility of MTES in water. The finally prepared $\mathrm{SiO}_{2}$ sol is shown in Fig. S1. $\dagger$ It is apparent from the optical photograph that the synthesized $\mathrm{SiO}_{2}$ sol was milky. In addition, we found that the hydrolysis time for methyltriethoxysilane was an important factor for controlling the $\mathrm{SiO}_{2}$ sol morphology. Fig. S2 $\uparrow$ shows the TEM images of the $\mathrm{SiO}_{2}$ sol with different hydrolysis times from $12 \mathrm{~h}$ to $60 \mathrm{~h}$. As the TEM images show, the diameter of the $\mathrm{SiO}_{2}$ particles was about $30 \mathrm{~nm}$ regardless of the hydrolysis time, but a difference lay in the extent of the polycondensation between the $\mathrm{SiO}_{2}$ particles. When the reaction was allowed to occur for $12 \mathrm{~h}$, the extent of the polycondensation of the $\mathrm{SiO}_{2}$ particles was relatively low and there was a large gap between the particles. The opposite was the case when the hydrolysis time was $60 \mathrm{~h}$. Based on the above results, the determined hydrolysis time was $36 \mathrm{~h}$, which was considered to be the optimum time for preparing the $\mathrm{SiO}_{2}$ sol, and all of the samples mentioned later were fabricated using $\mathrm{SiO}_{2}$ sol that was reacted for $36 \mathrm{~h}$ unless noted otherwise. Subsequently, the as-prepared $\mathrm{SiO}_{2}$ sol and the ForaperLe 323 (FL323) (which is a kind of fluorocarbon surfactant consisting of a waterborne acrylic fluoropolymer) were well-dispersed in an alkaline aqueous system. Tetraethoxysilane (TEOS) and PFDTES were added in the following step. After constant stirring for $24 \mathrm{~h}$, the preparation process was finished. Changes to the chemical bonding during fabrication are shown in Fig. S3. $\uparrow$ The inset optical image in Fig. 1b is a photograph of the as-prepared waterborne paint, indicating that the solution was semitransparent. The dynamic light scattering (DLS) measurements shown in Fig. 1b revealed that the average diameter of the waterborne paint was approximately $660 \mathrm{~nm}$. The most positive aspect was that the waterborne superamphiphobic paint could be prepared on a large scale (Fig. S4†) with an acceptable cost, which can be seen as a breakthrough in the application fields of waterborne superamphiphobic coatings. Fig. 1c shows the FTIR spectra of the as-prepared $\mathrm{SiO}_{2}$ sol and coating, indicating that the $\mathrm{SiO}_{2}$ sol was successfully modified by PFDTES in the aqueous system. For the $\mathrm{SiO}_{2}$ sol, the asymmetric stretching vibration of $\mathrm{Si}-\mathrm{O}-\mathrm{Si}$ gave strong absorption peaks at $1033 \mathrm{~cm}^{-1}$ and $1120 \mathrm{~cm}^{-1}$. The absorption peak at $782 \mathrm{~cm}^{-1}$ can be assigned to the presence of Si-C bonds, while the strong bands at $1409 \mathrm{~cm}^{-1}, 2935 \mathrm{~cm}^{-1}$ and $2973 \mathrm{~cm}^{-1}$ can 
a

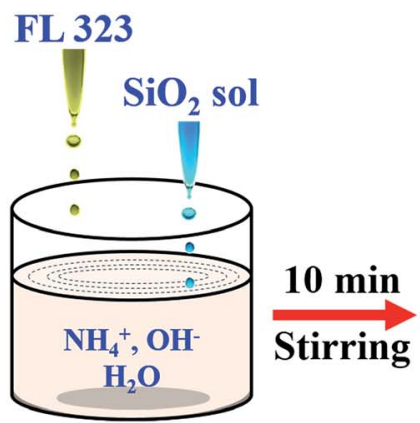

TEOS

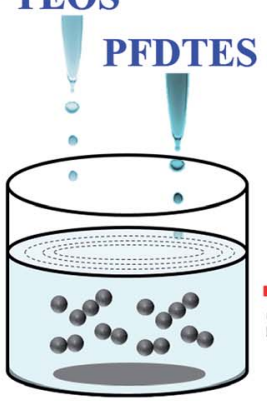

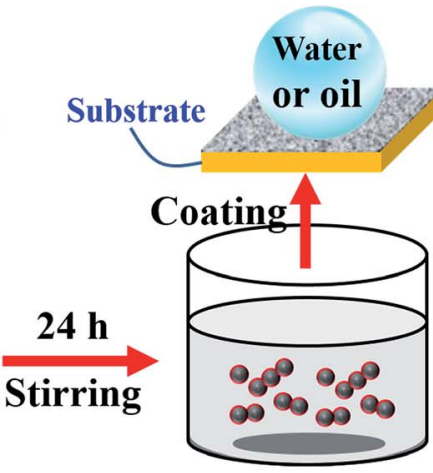

b
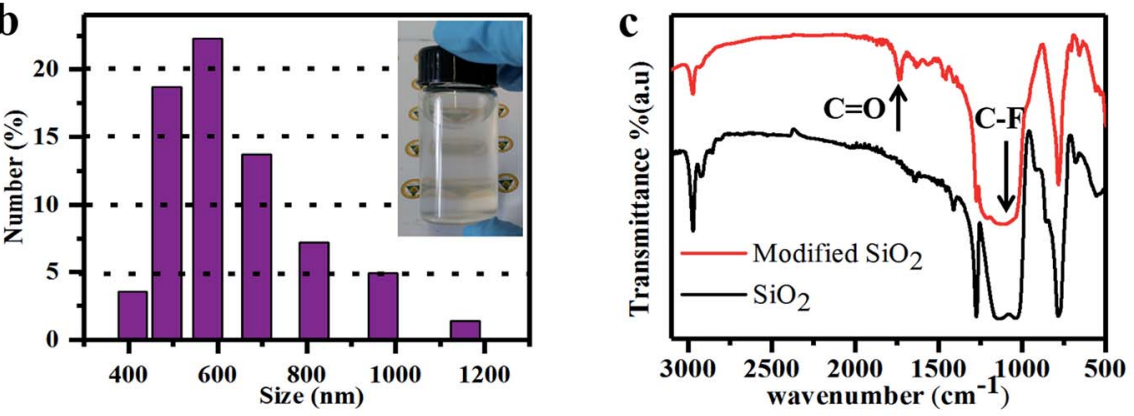

Fig. 1 Preparation of the waterborne superamphiphobic coating. (a) Schematic of the fabrication of the superamphiphobic coating. (b) Size distribution in the waterborne superamphiphobic paint (inset: photograph of the waterborne superamphiphobic paint in a transparent glass bottle). (c) FTIR spectra of the $\mathrm{SiO}_{2}$ sol and the waterborne superamphiphobic coating (all the samples were dried into a powder at $80{ }^{\circ} \mathrm{C}$ to test FTIR).

be attributed to the asymmetrical stretching of the $-\mathrm{CH}_{3}$ groups. After being modified, the FTIR spectra sketch of $\mathrm{SiO}_{2}$ had a significant change. Apart from the absorption peaks attributed to $\mathrm{SiO}_{2}$ that were mentioned before, the modified $\mathrm{SiO}_{2}$ had a new absorption peak at $1725 \mathrm{~cm}^{-1}$, which can be assigned to the symmetric stretching vibration of $\mathrm{C}=\mathrm{O}$ in the fluorocarbon surfactant. As we know, the characteristic peaks of the various stretching vibrations of $-\mathrm{CF}_{2}$ and $-\mathrm{CF}_{3}$ are at 1121, 1145, 1198, and $1241 \mathrm{~cm}^{-1}$, which are very close to the asymmetric stretching vibrations of Si-O-Si at $1033 \mathrm{~cm}^{-1}$ and $1120 \mathrm{~cm}^{-1}$. As a consequence, the width of the absorption peak was enlarged distinctly.

\subsection{Effect of the hydrolysis time for methyltriethoxysilane on the coating}

As mentioned before, the hydrolysis time of methyltriethoxysilane had an important effect on the $\mathrm{SiO}_{2}$ sol morphology, which is considered to be one of the principal factors in preparing superamphiphobic surfaces. As Fig. 2a shows, with the changing hydrolysis time, the coatings were all superrepellent to water (surface tension: $72.1 \mathrm{mN} \mathrm{m}^{-1}$ ) and soybean oil $\left(35.7 \mathrm{mN} \mathrm{m}^{-1}\right)$, but only a few coatings were superrepellent to hexadecane $\left(27.5 \mathrm{mN} \mathrm{m}^{-1}\right)$. When the hydrolysis time for methyltriethoxysilane was $36 \mathrm{~h}$, the coating had a maximum contact angle $\left(150^{\circ}\right)$ and minimum sliding angle $\left(6.3^{\circ}\right)$ to hexadecane, indicating that this coating had the best superamphiphobicity. The reason for this lies in the final morphology of the coatings, and scanning electron microscopy (SEM) images are shown in Fig. 2b-d. Compared to the other two coatings (where the hydrolysis time of methyltriethoxysilane is $12 \mathrm{~h}$ (Fig. 2b) and $60 \mathrm{~h}$ (Fig. 2d)), the coating prepared using the $\mathrm{SiO}_{2}$ sol that was hydrolyzed for $36 \mathrm{~h}$ (Fig. 2c) had a more compact and uniform morphology at the micro-scale. Furthermore, the network structure in Fig. 2c had fewer microholes than the two other coatings did. A similar case appeared when the magnification times were enlarged at the nano-scale. The coating with the $\mathrm{SiO}_{2}$ that had reacted for $36 \mathrm{~h}$ had more roughness to its structure and the nanoparticles in this sample were denser than they were in the two other coatings. The dense and uniform micro-nano structure resulted in better repellency of hexadecane. The fracture surface morphology of the superamphiphobic coating is presented in Fig. S5 $\uparrow$ and the upside-down circular truncated cone structure (which was called the "reentrant structure") could be seen clearly, resulting in the superamphiphobicity of our prepared coating.

\subsection{Applicability of the waterborne coatings on various substrates}

In order to test the superamphiphobicity on various substrates, three typical materials were selected: flat (glass), porous (copper foam) and soft (polyester fiber) substrates. As showed in the left position of Fig. 3a-c, all three substrates revealed excellent superhydrophobicity and there was no distinct change in the original state of the substrates after being coated. For example, the coated glass was translucent and we could see the badge beneath the substrates clearly. The water and oil contact angles and sliding angles are presented in Fig. S6. $\dagger$ For the contact 
a

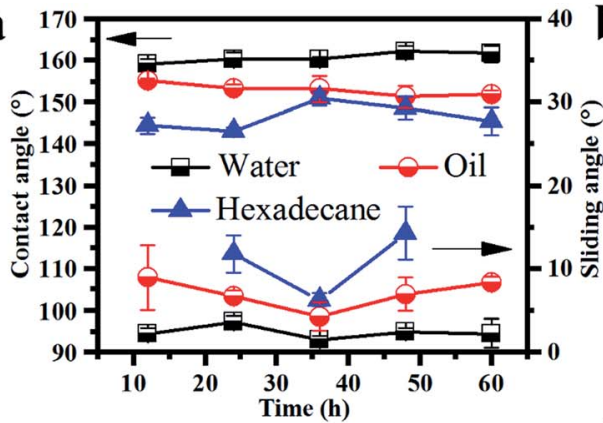

c

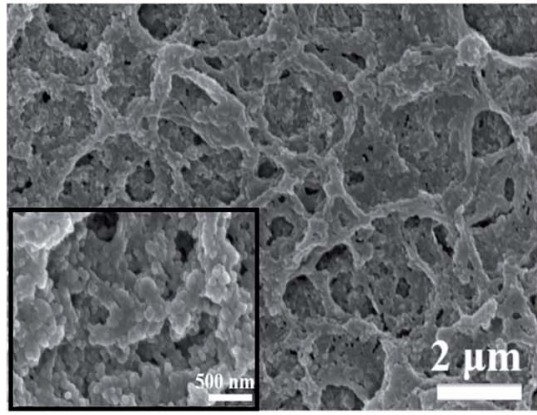

b

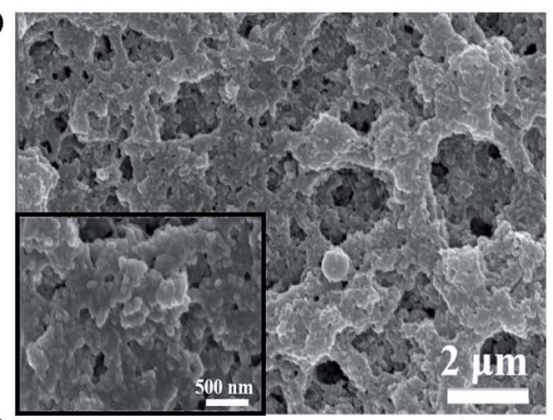

d

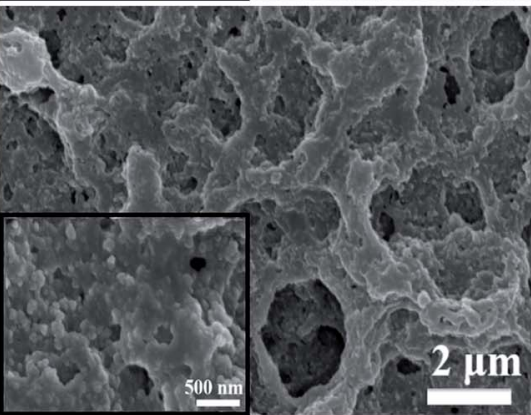

Fig. 2 (a) Contact angles and sliding angles of water, oil and hexadecane on the waterborne coating with different hydrolysis times of methyltriethoxysilane. SEM images of the waterborne coatings with hydrolysis times of methyltriethoxysilane of (b) $12 \mathrm{~h}$, (c) $36 \mathrm{~h}$ and (d) $60 \mathrm{~h}$.

angle values, these were about $160^{\circ}$ and $153^{\circ}$ for water and oil, respectively. For the sliding angle values, the values for glass and copper foam were all below $10^{\circ}$ for both water and oil. However, for fiber, the sliding angle was relatively large $\left(15^{\circ}\right.$ and $37^{\circ}$ for water and oil, respectively) due to the coarser texture of the fiber resulting in strong adhesion between the substrate and the liquid drop. When the volume of tested liquid (water and oil) was set at $25 \mu \mathrm{L}$, the sliding angle values decreased sharply to $7^{\circ}$ and $16^{\circ}$ for water and oil, respectively. We also chose some commercial fabrics to test and both showed an excellent superamphiphobicity (Fig. S7†). Based on the results above, we believe that the waterborne coating has an outstanding applicability on various substrates (for more details, see Video S1 $\dagger$ ).

The middle position of Fig. 3a-c shows the SEM images of the different substrates (the original morphologies of the copper foam and polyester fiber are listed in Fig. S8†) after

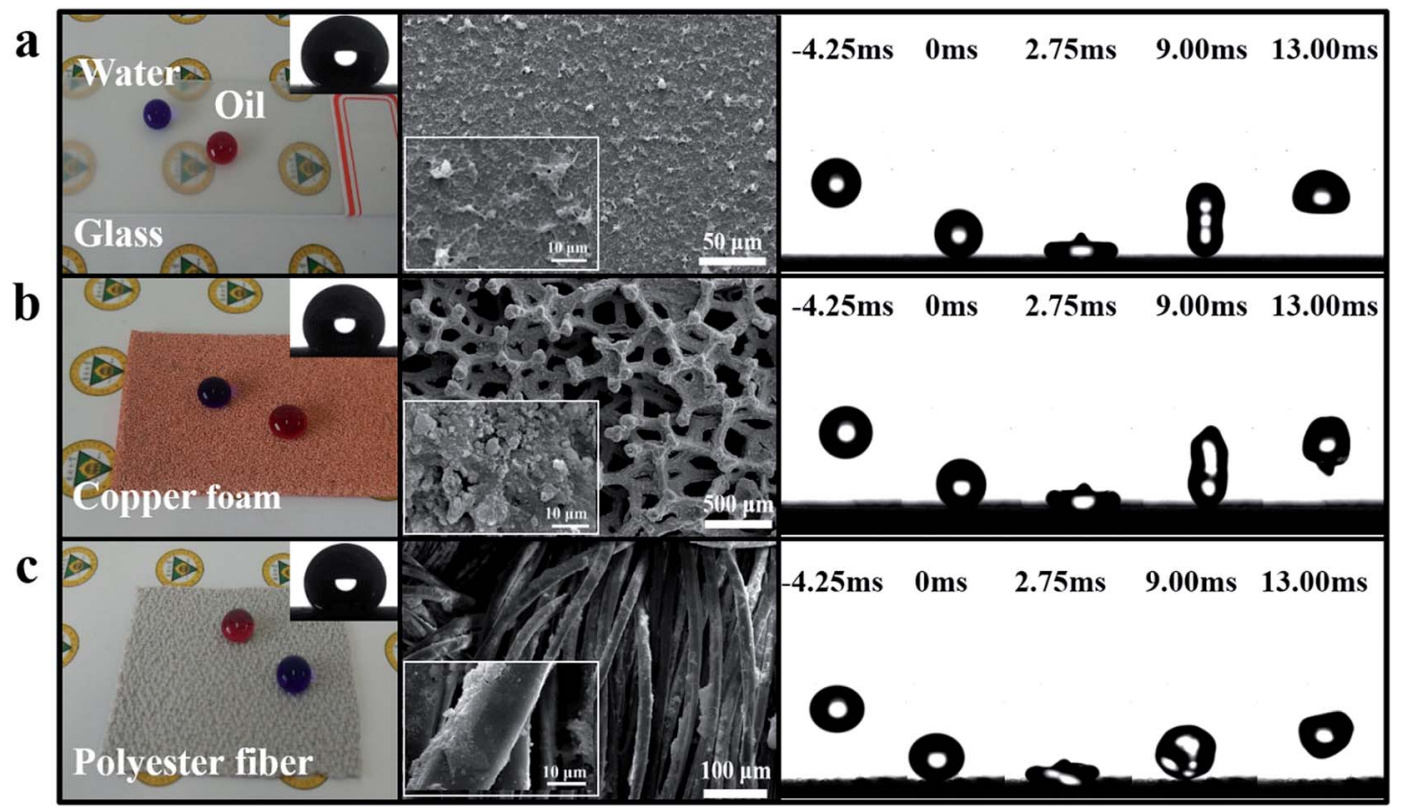

Fig. 3 Photographs (left, inset: oil contact angle images), SEM images (middle) and impacting test results (right, with a volume of $5 \mu \mathrm{L}$ and a height of $15 \mathrm{~mm}$ between the water droplet and the substrate) on (a) glass, (b) copper foam and (c) polyester fiber substrates. 
being coated with the waterborne paints, showing the textured surface morphologies for each one. The right position shows the high speed camera images of the bouncing water droplets on the various substrates (the height between the water drop and the substrate was $15 \mathrm{~mm}$, and the volume of water was 5 $\mu \mathrm{L})$. The water droplets could completely leave the surface without wetting, penetrating or damaging it for both the hard and soft substrates, showing that water has an extremely low adhesion with the various substrates. Based on the facts above, we believe that the coatings could stabilize on different substrates through the spraying or dip-coating method..$^{36,37}$

\subsection{Thermal stability}

It was unknown whether the as-prepared coatings could remain superamphiphobic under high temperature. Therefore, the water and oil contact angles and sliding angles under temperatures ranging from $100{ }^{\circ} \mathrm{C}$ to $300{ }^{\circ} \mathrm{C}$ were investigated to evaluate the thermal stability of the coating. As shown in Fig. 4a, when the temperature was below $200{ }^{\circ} \mathrm{C}$, the coating still remained superamphiphobic and there was no visible change in the water and oil contact angles and sliding angles. However, the coating became oleophilic and superoleophilic when the temperature increased to $250{ }^{\circ} \mathrm{C}$ and $300{ }^{\circ} \mathrm{C}$, respectively, while it remained as superhydrophobic as before. However, the coating was still superamphiphobic after $150{ }^{\circ} \mathrm{C}$ heating for $48 \mathrm{~h}$ (Fig. S9†).

It was interesting that the coating treated at $300{ }^{\circ} \mathrm{C}$ (which was superhydrophobic and superoleophilic) returned to being superamphiphobic after being deposited in a layer of PFDTES (namely the fluorination mentioned in Fig. 4b). Based on the results above, we believed that the coating becoming superoleophilic was attributed to the degradation of the substance containing the F element. SEM images and energy dispersive spectrometry (EDS) were measured to prove this point. As shown in Fig. 4c and d, the structure of the asprepared coating and the coating treated at $300{ }^{\circ} \mathrm{C}$ had little change, but the content of the $\mathrm{F}$ and $\mathrm{C}$ elements decreased sharply, while there was no obvious change in the content of $\mathrm{Si}$ after treating at $300{ }^{\circ} \mathrm{C}$ (the whole EDS is listed in Fig. S10 $\dagger$ ), indicating that the fluorocarbon surfactant degraded during the heating process.

\subsection{Chemical durability}

In addition to high temperature, the superamphiphobicity of coatings tends to recede when they are exposed to corrosive environments such as strong acid, base and high salt spray. Herein, we put the coated glasses into different $\mathrm{pH}$ values from 1 to 13 and into $1 \mathrm{~mol} \mathrm{~L}^{-1} \mathrm{NaCl}$ solutions and immersed them for $2 \mathrm{~h}$ to test the chemical durability of the coatings. Fig. S11a $\dagger$ shows digital photographs of the coatings that were immersed in different corrosive solutions and after immersing for $2 \mathrm{~h}$, revealing that the surfaces were all clean and there were no residual liquids on the coated glasses. More importantly, the coated glasses could keep clean even when immersed in oil after $2 \mathrm{~h}$ of immersion in different corrosive solutions (Fig. S11b †). The water and oil contact angle and sliding angle values are listed in Fig. 5a and b. As the results show, the contact angle values were all close to $160^{\circ}$ and $150^{\circ}$ and the sliding angle values were still below $10^{\circ}$ and $15^{\circ}$ for water and oil, respectively. In other words, the coating could withstand different corrosive environments for a certain time.


Fig. 4 Thermal stability of the coating. (a) Change in the contact angles and sliding angles (water and oil) with the temperature increasing from $100^{\circ} \mathrm{C}$ to $300^{\circ} \mathrm{C}$ for $2 \mathrm{~h}$ (inset: water and oil contact angle images). (b) Optical photographs of the coating on the glass substrate after $300{ }^{\circ} \mathrm{C}$ heating and after fluorination (inset: oil contact angle images). SEM images before $300^{\circ} \mathrm{C}$ heating (c) and after heating (d) (inset table: content of $\mathrm{F}$ and Si elements). 

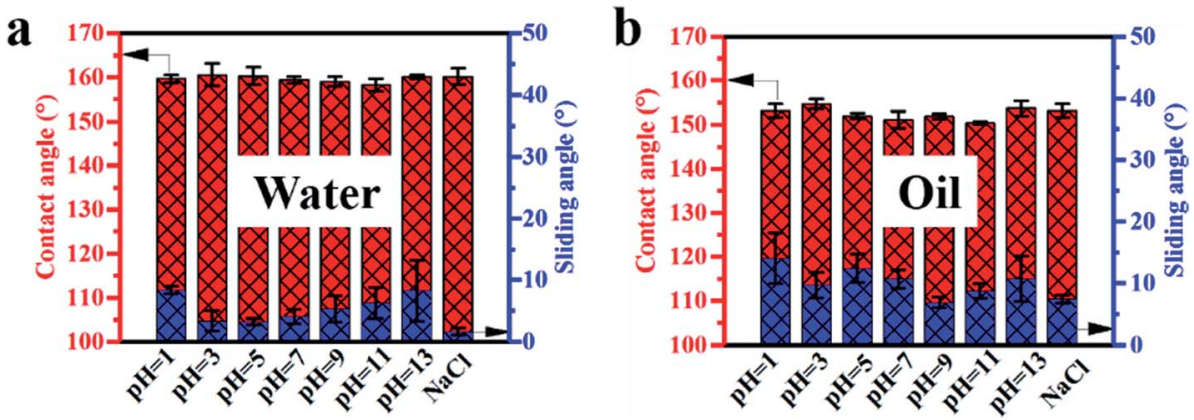

Fig. 5 Change in the contact angles and sliding angles for water (a) and oil (b) in different corrosive solutions after immersing for $2 \mathrm{~h}$.

\subsection{Applications of the waterborne coating}

Antifouling and self-cleaning properties. As we know, superhydrophobic surfaces can always remain clean under various conditions because of self-cleaning effects. Nevertheless, whether the surfaces can still remain clean under the severe conditions contained in oil fouling has rarely been reported.

We chose a glove and dyed water and oil to test the antifouling properties. The index finger of the glove was treated with the coating and the middle finger was untreated, as shown in Fig. S12a. $\uparrow$ Then the two fingers were immersed in the dyed oil simultaneously for several minutes. After being taken out, the index finger didn't have any oil stains on it while the middle finger was wetted by the dyed oil completely. Even after bending several times, the index finger could still remain completely clean. Based on the results above, we are convinced that the waterborne coating is able to be qualified in the antifouling field under most conditions. As for the self-cleaning properties test, ordinary sludge powder and sludge powder containing oil fouling were used to simulate a complex environment. As shown in Fig. S12b, $\uparrow$ the as-prepared coating exhibits excellent self-cleaning properties and water (dyed blue) can roll-off from the surface without a hitch, and as a result of which, the sludge powder can be taken away (for more details, see Video S2 $\dagger$ ). When the sludge powder containing oil fouling (a mixture of edible oil and sludge powder) was used, the mixture could also slide from the surfaces (Video S3 $\dagger$ ). In the end, there was no residue on the surfaces, indicating that the coatings have excellent self-cleaning properties under various complicated conditions.

Damp-proof testing on polyester fiber. Fibers tend to go mouldy when they are in a humid environment, and as a result of which, damp-proof properties are one of the most primary demands for various fibers. It is universally acknowledged that superhydrophobic surfaces have an excellent performance in the water-proof field. However, it remains in doubt whether all

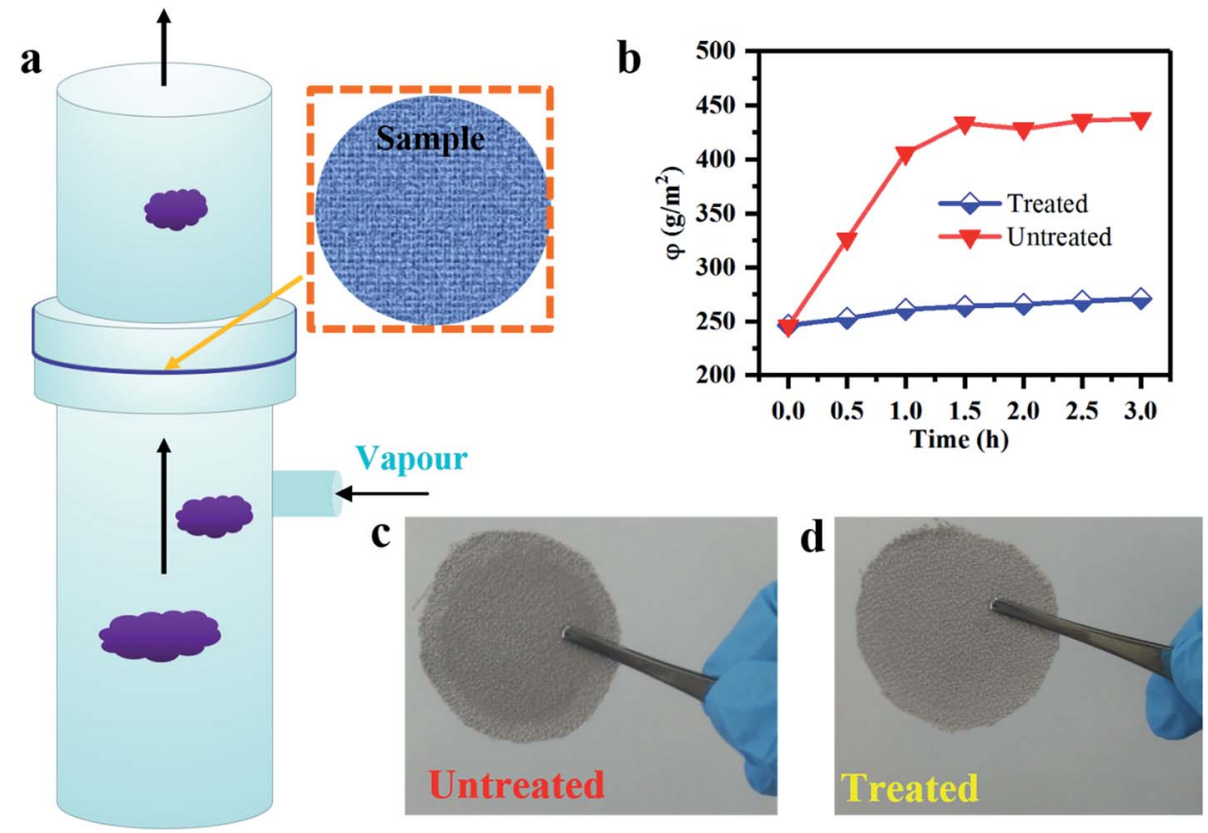

Fig. 6 Damp-proof test on polyester fiber. (a) Schematic of the damp-proof test. (b) Unit area mass change of the treated and untreated fibers at a certain humidity. Photograph of the untreated fiber (c) and treated fiber (d). 
superhydrophobic surfaces are capable in humid environments. Fig. 6a shows the schematic of the damp-proof test, in which two glass tubes and a humidifier were used. The samples were fixed between the two glass tubes (detailed data of the samples and glass tubes are listed in Fig. S13 $\dagger$ ) and the dampness was brought in from below and allowed to get out at the top. The mass of the sample was recorded every half hour and an ordinary fiber was introduced for comparison. Here, $\varphi$ is defined as the unit area mass of growth:

$$
\varphi=\frac{m-m_{0}}{S}
$$

where $m$ is the current mass, $m_{0}$ is the initial mass and $S$ is the area of the sample. As shown in Fig. 6b, the $\varphi$ value of the untreated fiber had a rapid increase from 0 to $1.5 \mathrm{~h}$, while no discernible changes were observed in the treated fiber. Other treated and untreated fibers showed little obvious growth in the $\varphi$ value after $1.5 \mathrm{~h}$, indicating that the ordinary fiber was wetted entirely by the dampness, whereas there was little effect on the superhydrophobic fiber (Fig. 6c and d). More importantly, the treated fiber had equal breathability as the untreated did (Video $\mathrm{S} 4 \dagger)$.

\section{Conclusion}

In conclusion, we have demonstrated a simple, low cost, environmentally friendly method to fabricate absolutely waterborne superamphiphobic coatings using methyltriethoxysilane, fluorinated alkyl silane and a fluorocarbon surfactant. The coating showed an excellent superamphiphobic ability with contact angles of $160^{\circ}, 153^{\circ}$ and $150^{\circ}$ and sliding angles of $1^{\circ}, 4.7^{\circ}$ and $6.3^{\circ}$ with respect to water, soybean oil and hexadecane. The coating could be applied on various substrates, such as glass, copper foam and polyester fiber, through spraying or dipcoating. Furthermore, after immersing in acid $(\mathrm{pH}=1)$, alkali $(\mathrm{pH}=13)$ and salt $\left(1 \mathrm{~mol} \mathrm{~L}^{-1} \mathrm{NaCl}\right)$, and after treating at $200{ }^{\circ} \mathrm{C}$ for $2 \mathrm{~h}$, the coating still maintained its superamphiphobic ability. Additionally, this superamphiphobic coating exhibited prospective performance for anti-fouling, self-cleaning and damp-proof applications.

\section{Conflicts of interest}

There are no conflicts to declare.

\section{Acknowledgements}

We are grateful for the support received from the National Natural Science Foundation of China (Grants 51671055, 51676033) and the China National Key R\&D Program (2016YFC0700304).

\section{References}

1 A. K. Mohanty, M. Misra and L. T. Drzal, J. Polym. Environ., 2002, 10, 19-26.
2 A. Tuteja, W. Choi, M. L. Ma, J. M. Mabry, S. A. Mazzella, G. C. Rutledge, G. H. McKinley and R. E. Cohen, Science, 2007, 318, 1618-1622.

3 D. Prat, J. Hayler and A. Wells, Green Chem., 2014, 16, 45464551.

4 Y. Lu, S. Sathasivam, J. L. Song, C. R. Crick, C. J. Carmalt and I. P. Parkin, Science, 2015, 347, 1132-1135.

5 X. Deng, L. Mammen, H. J. Butt and D. Vollmer, Science, 2012, 335, 67-70.

6 R. Furstner, W. Barthlott, C. Neinhuis and P. Walzel, Langmuir, 2005, 21, 956-961.

7 G. Wen, X. Y. Gao, P. Tian, L. S. Zhong, Z. L. L. Wang and Z. G. Guo, Chem. Eng. J., 2018, 346, 94-103.

8 M. J. Kreder, J. Alvarenga, P. Kim and J. Aizenberg, Nat. Rev. Mater., 2016, 1(1), 15003.

9 L. Mishchenko, B. Hatton, V. Bahadur, J. A. Taylor, T. Krupenkin and J. Aizenberg, ACS Nano, 2010, 4, 76997707.

10 L. L. Cao, A. K. Jones, V. K. Sikka, J. Z. Wu and D. Gao, Langmuir, 2009, 25, 12444-12448.

11 P. Guo, Y. M. Zheng, M. X. Wen, C. Song, Y. C. Lin and L. Jiang, Adv. Mater., 2012, 24, 2642-2648.

12 K. Golovin, S. P. R. Kobaku, D. H. Lee, E. T. DiLoreto, J. M. Mabry and A. Tuteja, Sci. Adv., 2016, 2(3), e1501496.

13 W. W. Zhang, S. L. Wang, Z. Xiao, X. Q. Yu, C. H. Liang and Y. F. Zhang, Langmuir, 2017, 33, 8891-8898.

14 J. Ou, B. Perot and J. P. Rothstein, Phys. Fluids, 2004, 16, 4635-4643.

15 M. J. Cheng, M. M. Song, H. Y. Dong and F. Shi, Small, 2015, 11, 1665-1671.

16 X. B. Zhang, J. Zhao, Q. Zhu, N. Chen, M. W. Zhang and Q. M. Pan, ACS Appl. Mater. Interfaces, 2011, 3, 2630-2636.

17 P. Calcagnile, D. Fragouli, I. S. Bayer, G. C. Anyfantis, L. Martiradonna, P. D. Cozzoli, R. Cingolani and A. Athanassiou, ACS Nano, 2012, 6, 5413-5419.

18 L. Feng, Z. Y. Zhang, Z. H. Mai, Y. M. Ma, B. Q. Liu, L. Jiang and D. B. Zhu, Angew. Chem., Int. Ed., 2004, 43, 2012-2014.

19 B. Wang, W. X. Liang, Z. G. Guo and W. M. Liu, Chem. Soc. Rev., 2015, 44, 336-361.

20 H. Zhu, L. Gao, X. Yu, C. Liang and Y. Zhang, Appl. Surf. Sci., 2017, 407, 145-155.

21 X. Yin, C. C. Sun, B. Zhang, Y. Z. Song, N. C. Wang, L. P. Zhu and B. K. Zhu, Chem. Eng. J., 2017, 330, 202-212.

22 T. Gong, J. Kim, J. Y. Woo, J. H. Jang, S. E. Lee and C. S. Han, RSC Adv., 2017, 7, 25796-25802.

23 Y. M. Zheng, H. Bai, Z. B. Huang, X. L. Tian, F. Q. Nie, Y. Zhao, J. Zhai and L. Jiang, Nature, 2010, 463, 640-643.

24 A. R. Parker and C. R. Lawrence, Nature, 2001, 414, 33-34.

25 M. Wang, Q. Liu, H. Zhang, C. Wang, L. Wang, B. Xiang, Y. Fan, C. F. Guo and S. Ruan, ACS Appl. Mater. Interfaces, 2017, 9, 29248-29254.

26 B. X. Leng, Z. Z. Shao, G. de With and W. H. Ming, Langmuir, 2009, 25, 2456-2460.

27 C. Aulin, S. H. Yun, L. Wagberg and T. Lindstrom, ACS Appl. Mater. Interfaces, 2009, 1, 2443-2452.

28 K. Zhao, K. S. Liu, J. F. Li, W. H. Wang and L. Jiang, Scr. Mater., 2009, 60, 225-227. 
29 H. Zhao, K. Y. Law and V. Sambhy, Langmuir, 2011, 27, 59275935.

30 H. Jin, M. Kettunen, A. Laiho, H. Pynnonen, J. Paltakari, A. Marmur, O. Ikkala and R. H. A. Ras, Langmuir, 2011, 27, 1930-1934.

31 A. Susarrey-Arce, A. G. Marin, S. Schlautmann, L. Lefferts, J. G. E. Gardeniers and A. van Houselt, J. Micromech. Microeng., 2012, 23(2), 025004.

32 D. T. Ge, L. L. Yang, Y. F. Zhang, Y. Rahmawan and S. Yang, Part. Part. Syst. Charact., 2014, 31, 763-770.
33 H. Zhou, H. Wang, H. Niu, J. Fang, Y. Zhao and T. Lin, Adv. Mater. Interfaces, 2015, 2(6), 1400559.

34 H. Liu, J. Y. Huang, Z. Chen, G. Q. Chen, K. Q. Zhang, S. S. AlDeyab and Y. K. Lai, Chem. Eng. J., 2017, 330, 26-35.

35 A. Milionis, K. Dang, M. Prato, E. Loth and I. S. Bayer, J. Mater. Chem. A, 2015, 3, 12880-12889.

36 C. Schlaich, L. Yu, L. Cuellar Camacho, Q. Wei and R. Haag, Polym. Chem., 2016, 7, 7446-7454.

37 C. Schlaich, L. Cuellar Camacho, L. Yu, K. Achazi, Q. Wei and R. Haag, ACS Appl. Mater. Interfaces, 2016, 8, 29117-29127. 